\title{
Modified Component Separation with One Rectus Abdominis Muscle: Reply to Letter
}

\author{
Adrian Dragu · Frank Unglaub · Raymund E. Horch
}

Published online: 7 October 2009

(C) Société Internationale de Chirurgie 2009

We are grateful to Dr. Dadhwal for his interest in our recently published article [1]. Special thanks for his important comments regarding Figure $1 \mathrm{~b}$. Of course, his doubt about the accuracy of the original illustration is justified; it is correct that the human body has two rectus abdominis muscles. We have corrected Figure $1 \mathrm{~b}$ to show this. Nevertheless, a modified component separation for smaller defects is still possible when the patient has only one rectus abdominis muscle. This might be the situation in a patient with an unstable scar or hernia of the abdominal wall (e.g., after laparotomy, infection, etc.) and as a result of the previous use of a vertical rectus abdominis myocutaneous (VRAM) flap or transverse rectus abdominis myocutaneous (TRAM) flap (e.g., after breast reconstruction, closure of groin defects, etc.).

\section{Reference}

1. Dragu A, Klein P, Unglaub F et al (2009) Tensiometry as a decision tool for abdominal wall reconstruction with component separation. World J Surg 33:1174-1180

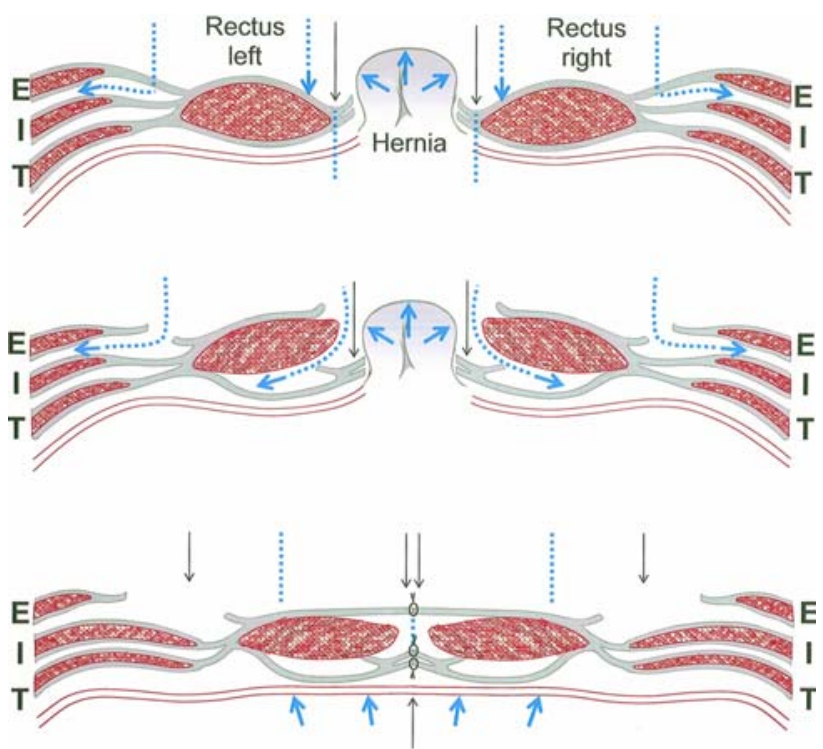

Fig. 1 b Components of anatomic separation technique by Ramirez modified after "Reoperative Aesthetic and Reconstructive Plastic Surgery" by James C. Grotting, Vol. II, 1995. Transversal view. E external oblique muscle, $I$ internal oblique muscle, $T$ transversus abdominis muscle. The left rectus abdominis muscle is now included
A. Dragu $(\bowtie) \cdot$ F. Unglaub · R. E. Horch

Department of Plastic and Hand Surgery, University Hospital

Erlangen, Krankenhausstrasse 12, 91054 Erlangen, Germany

e-mail: adrian.dragu@uk-erlangen.de 